\title{
Design of Model Reference Adaptive Control for Nonlinear Multivariable Systems
}

\author{
Yasuhiko Mutoh Member (Sophia University, y_mutou@sophia.ac.jp)
}

Keywords: nonlinear system, multivariable system, interactor, adaptive control, a prior information

A goal of this paper is to construct the adaptive output tracking controller for nonlinear multivariable systems with unknown parameters. For this purpose, an interactor for a nonlinear system is used as a prior information of the unknown plant. If the interactor is diagonal, the problem becomes straightforward extension of the adaptive control problem for scalar systems. However, in general, as in the linear case, the interactor is a lower left triangular polynomial matrix whose off-diagonal elements depend on the unknown plant parameters, which is the most difficult point in the multivariable case.

The m-input m-output nonlinear unknown plant considered in this paper is as follows.

$$
\left\{\begin{array}{l}
\dot{x}=f(x)+g(x) u \\
y=h(x)
\end{array}\right.
$$

A polynomial matrix of the differencial operator $p$ with coefficient matrices, $N_{i} \in R^{m \times m}$

$$
N(p)=N_{w} p^{w}+N_{w-1} p^{w-1}+\cdots+N_{0}
$$

is an interactor of the above non-linear system if it satisfies the following equation.

$$
N(p) y(t)=a(x)+\Lambda(x) u(t)
$$

Here, $\Lambda(x)$ is a nonsingular matrix. In this paper, first, using the interactor algorithm, the structure of the interactor of the unknown plant is estimated, and then, besed on this knowledge, the adaptive output tracking control system will be designed by applying the well developed MRACS technique for linear systems.

What we can do using this technique can be shown as the following example.

[Example] Consider the unknow nonlinear plant (1) with

$$
\begin{aligned}
& f(x)=\left[\begin{array}{c}
a_{1} x_{1}^{2}+a_{2} x_{2} \\
a_{3} x_{1} x_{3} \\
-a_{4} x_{1}+a_{5} x_{3} \\
0
\end{array}\right] \\
& g(x)=\left[\begin{array}{cc}
0 & 0 \\
0 & a_{6} \\
a_{7} & 0 \\
a_{8} & 0
\end{array}\right], h(x)=\left[\begin{array}{l}
x_{3} \\
x_{4}
\end{array}\right]
\end{aligned}
$$

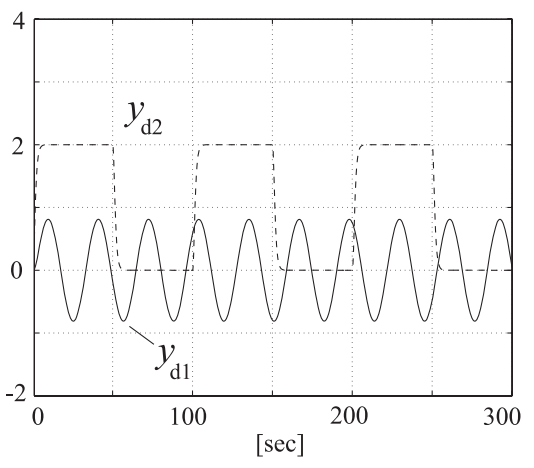

Fig. 1. Output of the Reference Model

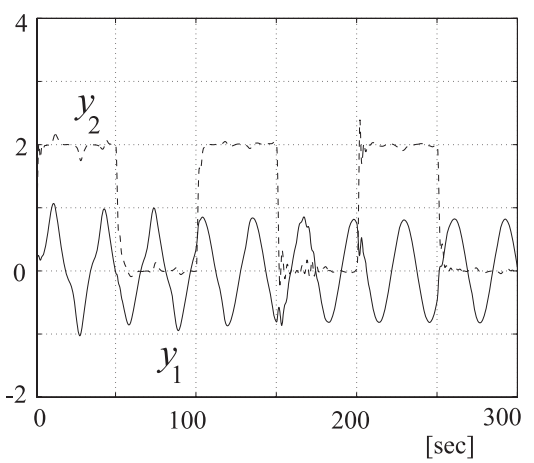

Fig. 2. Plant Output (Adaptive Control)

where $x=\left[x_{1}, x_{2}, x_{3}, x_{4}\right]^{T}, y=\left[y_{1}, y_{2}\right]^{T}, \quad u=\left[u_{1}, u_{2}\right]^{T}$ are the state, the output and the input respectively. The parameters, $a_{1} \sim a_{8}$, are unknown constants whose true values are all 1. According to the interactor algorithm, the following is the estimate of the structure of the interactor of this unknown plant,

$$
N(\psi, p)=\left[\begin{array}{cc}
p+1 & 0 \\
\psi_{1} p^{3}+\psi_{2} p^{2} & p^{3}+6 p^{2}+11 p+6
\end{array}\right]
$$

where $\psi_{1}$ and $\psi_{2}$ are unknown parameters which we have to estimate in the adaptive controller. Then using $N(\psi, p)$, the MRACS for the system (1) can be designed. Fig.1 and Fig.2 show the reference output signals and adaptive output signals respectively in the simulation. This shows the validity of the proposed adaptive system. 


\title{
非線形多変数系に対する MRACS の一設計法
}

\author{
正 員 武藤 康彦*
}

\author{
Design of Model Reference Adaptive Control for Nonlinear Multivariable Systems
}

Yasuhiko Mutoh*, Member

\begin{abstract}
A goal of this paper is to construct the adaptive output tracking controller for nonlinear multivariable systems with unknown parameters. For this purpose, an interactor for nonlinear systems is used as a prior information of the unknown plant. If the interactor is diagonal, the problem becomes straightforward extension of the adaptive control problem for scalar systems. However, as in the linear case, the interactor is a lower left triangular polynomial matrix whose off-diagonal elements depend on the unknown parameters of the plant. In this paper, first, using the interactor algorithm, the structure of the interactor of the unknown plant is estimated, and then, the well developed MRACS technique for linear systems will be applied. Some simulation results will be presented to show the validity of this designe concept. This shows that the framework for designing the MRACS for linear multivariable systems can be also used for the nonlinear multivariable system.
\end{abstract}

キーワード : 非線形系, 多变数系, インタラク夕, 適応制御, 事前情報

Keywords: nonlinear system, multivariable system, interactor, adaptive control, a prior information

\section{1. まえがき}

本論文では非線形多変数系に対するモデル規範型適応制 御系（MRACS）の一設計法について述べる。近年，アファ イン型の非線形システムについて多くの研究が行われ (7) (8), バックステッピング手法に基づいた適応安定化制御に関し ていくつかの結果が得られている。

一方, 非線形システムにおいても相対次数が定義される ことから，出力を相対次数分だけ微分することにより，入 力と出力の関係を表す式を導出し, これに線形系に対して 培ってきた MRACS の手法 (2) (6) を適用することが考えら れる。さらに，あるクラスの非線形多変数系に対しては相 対次数を拡張したインタラク夕(1) (4) を定義することができ るため，これを利用して MRACS を構成することが考えら れる。

本論文は, 線形多変数系に対して従来より利用されてき たMRACS の設計のための枠組みが，あるクラスの非線形 多変数系に対してそのまま適用可能であることを示すこと を目的としている。このクラスとは静的状態フィードバッ クにより入出力線形化可能なアファイン型の非線形多変数

\footnotetext{
* 上智大学理工学部機能創造理工学科

干 102-8554 東京都千代田区紀尾井町 7-1

Dept. of Engineering and Applied Sciences, Sophia University

7-1 Kioicho, Chiyoda-ku, Tokyo 102-8554
}

系である。このクラスのプラントは線形系と同様に定数係 数行列を持つインタラクタが得られるため, 未知パラメー タが線形に含まれている場合は “generic”な意味でインタ ラクタの構造を推定することができる。一般にインタラク 夕は左下三角行列となり, 対角部分は推定により得られた 次数を持った任意安定多項式, 非対角部分はプラントのパ ラメータとインタラクタの対角成分に依存して決まる未知 パラメータを含んでいる。構造推定されたインタラクタを 用いて，プラントの別表現を得るところまでが，未知プラ ントの事前情報を取り扱う本論文の中心的なテーマとなる。 一旦，プラントの別表現が得られれば，これに基づいて 適応系を構成することができる。プラントが未知パラメー 夕を線形に含んでいる場合, プラントの別表現は未知パラ メータベクトルとリグレッサベクトルの積で表されること から, 線形系で培ってきた様々な形態の適応系を適用する ことが可能となる。

ここでは, 構造が比較的に簡単であるモデルマッチングの ためのコントローラを用いて，インタラクタに含まれる未 知パラメータとコントロールパラメータに対してパラメー 夕調整機構を適用して間接型の非線形多変数系の MRACS を構成する。以下，第 2 章では問題の記述，第 3 章で非線形 多変数系のインタラクタについて簡単にまとめ, 第 4 章で インタラクタアルゴリズムについて記述する。これは, 未 知プラントのインタラクタの構造推定をするときの道具と 
なる。適応系の構成については，第 5 章において最初に概 略を述べてから，例題を用いて設計手順を記述し，最後に シミュレーション結果を示す。

\section{2. 問題の記述}

未知プラントとして, 次式で示される $m$ 入力 $m$ 出力の 非線形多変数系を考える。

$$
\left\{\begin{array}{l}
\dot{x}=f(x)+g(x) u \\
y=h(x)
\end{array}\right.
$$

ここで, $x \in R^{n}, u, y \in R^{m}$ はそれぞれ状態変数, 入 力, 出力である。また, 関数 $f(x) \in R^{n}, g(x) \in R^{n \times m}$ $h(x) \in R^{m}$ は必要なだけ微分できるものとし，未知パラ メータは線形に含まれているものとする。さらに，システ ムは静的な状態フィードバックにより線形化可能なクラス を対象とする。ここで，規範入力 $r \in R^{m}$ に対して次式で 表される規範モデルを考えよう。

$$
y_{d}=G_{d}(p) r
$$

$G_{d}(p)$ は $p$ を微分演算子として表した伝達関数である。制 御目的は規範入力 $r$ に対してプラント (1) の出力 $y$ が規範 モデルの出力 $y_{d}$ に追従するような入力 $u$ を適応的に構成 することである。

\section{3. 非線形多変数系のインタラクタ}

ここでは, 非線形系多変数系のインタラクタについて簡 単にまとめておく。

〔定義 1〕 定数行列 $N_{i} \in R^{m \times m}(i=1,2, \cdots, \omega)$ を係数 に持つ多項式行列

$$
N(p)=N_{w} p^{w}+N_{w-1} p^{w-1}+\cdots+N_{0} \cdots(3)
$$

が次式を満足するとき $N(p)$ を領域 $\Omega$ でシステム $(1)$ の インタラクタと呼ぶ。

$$
N(p) y=a(x)+\Lambda(x) u . \quad{ }^{\forall} x \in \Omega .
$$

$\Lambda(x) \in R^{m \times m}$ はすべての $x \in \Omega$ で正則な行列である。以 下では簡単のため, $\Omega$ は全空間として議論を進める。

出力関数 $h(x)$ のリー微分を用いて次式により行列 $T_{i}(x) \in R^{m \times m}(i=1,2, \cdots)$ を定義する。

$$
T_{i}(x)=L_{g} L_{f}^{i-1} h(x) \quad(i=1,2, \cdots)
$$

さらにこの $T_{i}(x)$ を用いて次のブロック Toeplitz 行列 $\Gamma_{i}(x)(i=1,2, \cdots)$ を定義する。

$$
\begin{aligned}
\Gamma_{1}(x)= & T_{1}^{T}(x) \\
\Gamma_{i}(x)= & {\left[\begin{array}{ccc}
T_{1}^{T}(x) & & 0 \\
\vdots & \ddots & \\
T_{i}^{T}(x) & \cdots & T_{1}^{T}(x)
\end{array}\right] } \\
& (i=2,3, \cdots)
\end{aligned}
$$

このとき, インタラクタに関して以下の定理は基本的で
ある(4)。

〔定理 1〕 (3) 式で表される $N(p)$ がシステム $(1)$ のインタ ラクタとなるための必要十分条件は次式を満たすような 正則行列 $\Lambda(x) \in R^{m \times m}$ が存在することである。

$$
\Gamma_{w}(x)\left[\begin{array}{c}
N_{w}^{T} \\
N_{w-1}^{T} \\
\vdots \\
N_{1}^{T}
\end{array}\right]=\left[\begin{array}{c}
0 \\
\vdots \\
0 \\
\hline \Lambda^{T}(x)
\end{array}\right]
$$

(7) 式をインタラクタ方程式と呼ぶ。 $N(p)$ の次数 $w$ は 次の定理により決まる。

〔定理 2〕 (3) 式で表される $N(p)$ がシステム (1)のインタ ラクタであるとする。このとき $w$ は次式を満たす整数 $k$ の最小值である。

$$
\operatorname{rank} \Gamma_{k}(x)=\operatorname{rank} \Gamma_{k-1}(x)+m
$$

さて, システム $(1)$ がインタラクタ $N(p)$ を持っている とき, システムの入出力は (4) 式と表されることから, 状 態フィードバック

$$
u(t)=-\Lambda^{-1}(x) a(x)+\Lambda^{-1}(x) v(t)
$$

により, 外部入力 $v(t)$ から出力 $y(t)$ までは

$$
N(p) y=v
$$

と表され，この閉ループ伝達行列は $N^{-1}(p)$ となる。これ を非線形系多変数系の逆インタラクタ化と呼ぶ。ここで,

$$
\begin{gathered}
a(x)=\left[N_{0}, N_{1}, \cdots, N_{w}\right]\left[\begin{array}{c}
h(x) \\
L_{f} h(x) \\
\vdots \\
L_{f}^{w} h(x)
\end{array}\right] \\
\Lambda(x)=\left[N_{1}, N_{2}, \cdots, N_{w}\right]\left[\begin{array}{c}
L_{g} h(x) \\
L_{g} L_{f} h(x) \\
\vdots \\
L_{g} L_{f}^{w-1} h(x)
\end{array}\right]
\end{gathered}
$$

である。

非線形システム (1) に対して, 状態フィードバック (9) を 用いた全システムは以下の形をしたシステムに変数変換と フィードバック等価であることが知られている ${ }^{(8)}$ 。

$$
\begin{aligned}
& \dot{z}=F z+B v \\
& \dot{\xi}=\psi(\xi, z) \cdots
\end{aligned}
$$

ここで，(12) 式は（10）式の実現であり， $z \in R^{q}, \xi \in$ $R^{(n-q)}$ である。ただし, $q$ はシステム $(1)$ の相対次数の和 に相当しており， $N(p)$ の行列式の次数である。また, 一般 に $q \leq n$ であるので，隠れたモードが $(13)$ 式であり，

$$
\dot{\xi}=\psi(\xi, 0)
$$

はシステム $(1)$ のゼロダイナミクスである。 
したがって，閉ループが内部安定であるためにはシステ ム (1)のゼロダイナミクスがISS（有界入力に対して状態 変数が有界）である必要がある。これは線形多変数系が最 小位相系と仮定することに対応している。

$N(p)$ が対角であれば多変数系の取り扱いは格段に容易 となる。非線形多変数系でよく定義される「ベクトル相対 次数」とは $N(p)$ が対角となる場合の対角要素の多項式の 次数であり,このとき多変数制御系の設計はスカラ系を並 べたものとして取り扱える。しかし，一般的に $N(p)$ は左 下三角行列として得られ，このことが多变数系の制御問題 を複雑にしている。特に，適応制御問題では， $N(p)$ の対角 要素はその次数さえ決まれば任意の安定多項式に選ぶこと ができるが，非対角要素はインタラク夕方程式を解いて得 られるので，制御対象が未知パラメー夕を含んでいる場合 は $N(p)$ も未知となり, さらに問題を複雑にしている。こ れは線形多変数系と同じ状況である。

\section{4. インタラクタの構造推定}

インタラクタの次数構造は $\Gamma_{w}$ の列ベクトルの線形独立 性の構造により決まる。この線形独立な列べクトルを探す 手順をインタラクタ・アルゴリズムという。これは，未知 パラメータを含むシステムに対するインタラクタの構造推 定を行うためには必須のプロセスであるので，この節でま とめておく。以下では記述を簡単にするために最初から $w$ が決まっているとしてアルゴリズムを説明する。詳細は文 献（4）を参照されたい。

(6) 式より， $\Gamma_{i}$ は $i$ 個の列ブロックよりなり，各列ブロッ クは $m$ 個の列ベクトルよりなっている。ここで, $\gamma_{j}^{k}(x) に$ より $\Gamma_{i}$ の右から第 $k$ 番目の列ブロックにおいて, 左から 第 $j$ 番目の位置にある列ベクトルを表すものとする。以下 では簡単のため $i$ にかかわらずにこの表現を用いることに する。

\section{[インタラクタアルゴリズム]}

[Step 1] $\quad \Gamma_{1}(x)$ の左から順に列ベクトルの独立性 をチェックして，必要なら列の並べ替えを行うことにより， 左から連続的に独立な列べクトルが並び，残りはこれらの ベクトルに対して従属なべクトルとなるようにする。この 独立な列べクトルの数を $q_{1}$ とする。これらの独立な列べク トルを改めて,

$$
\gamma_{1}^{1}(x), \gamma_{2}^{1}(x), \cdots, \gamma_{q_{1}}^{1}(x)
$$

と表し，残りのベクトルを $\gamma_{q_{1}+1}^{1}(x), \cdots, \gamma_{m}^{1}(x)$ とする。こ こで行った列べクトルの並べ替えとは，すべての $T_{i}^{T}(x)$ の 対応する列の並べ替えを意味し，これは対応する出力信号 の並べ替えを意味する。また，以下で列の並べ替えを行っ た場合も並べ替えた後の列ベクトルを改めて $\gamma_{j}^{k}(x)$ と表記 する。これは，列べクトルを並べ替える毎に添え字が入れ 替わり，記述が煩雑になるのを防ぐためであり，適当に並 心゙替えたものを最初から考えればよいので，並べ替えは必 要ないとしても一般性は失わない。
[Step 2] $\Gamma_{2}(x)$ の第 2 列ブロックについて考える。 $\Gamma_{2}(x)$ の構造から第 2 列ブロック中の左から $q_{1}$ 個の列べ クトルは自動的に第 1 ，第 2 列ブロックにおける独立な列 ベクトルとなる。さらに，第 2 列ブロック中の残りの列べ クトルについて必要なら列の並べ替えを行って, 第 2 列ブ ロック中に左から連続的に $q_{2}$ 個 $\left(q_{2} \geq q_{1}\right)$ の独立な列ベ クトル（前Step で得られた独立ベクトルに対しても独立） を並べ,これらを改めて

$$
\gamma_{1}^{2}(x), \gamma_{2}^{2}(x), \cdots, \gamma_{q_{2}}^{2}(x)
$$

と書く。 $\gamma_{q_{2}+1}^{2}, \cdots, \gamma_{m}^{2}$ を第 2 列ブロック中の残りの列ベク トルとし，これらは互いに独立なべクトル $\gamma_{1}^{1}(x), \cdots, \gamma_{q_{1}}^{1}(x)$, $\gamma_{1}^{2}(x), \cdots, \gamma_{q_{2}}^{2}(x)$ に対して従属な列べクトルである。また, ここで行った列べクトルの並べ替えも [Step 1] と同様に出 力信号の並べ替えを意味している。

このような手順を繰り返して, $[$ Step $w]$ で初めて $q_{w}=m$ となったとし，ここでアルゴリズムを終了する。このとき，

$$
q_{1} \leq q_{2} \leq \cdots \leq q_{w-1}<q_{w}=m
$$

となっている。

Step $w$ までを終えた後, 各列ブロックにおける第 $j$ 番目 の列ベクトルの集合

$$
\gamma_{j}^{1}(x), \gamma_{j}^{2}(x), \cdots, \gamma_{j}^{w}(x) \quad j=1, \cdots, m
$$

を第 $j$ 系列の列ベクトルと呼ぶ。さらに，第 $j$ 系列の列べ クトルのうち，インタラクタアルゴリズムにより最初に独 立ベクトルとして選ばれた列べクトルを $\gamma_{j}^{k_{j}}(x)$ とする。明 らかに,

$$
k_{1} \leq k_{2} \leq \cdots \leq k_{m-1} \leq k_{m}=w \cdots \cdots \cdots \cdots
$$

が成立する。このとき, インタラクタの次数構造に関して 次のような性質がある ${ }^{(4)}$ 。

〔性質 1〕 インタラクタは $w\left(=k_{m}\right)$ 次の行プロパーな 左下三角多項式行列となり，第 $j$ 対角要素は $k_{j}$ 次の任意 多項式である。また，第 $j$ 行の行次数も $k_{j}$ 次である。さ らに, 対角要素を決めると非対角要素はインタラクタ方 程式により一意に定まる。さらに，インタラクタ方程式 によれば，インタラクタの非対角要素の多項式は 1 次の 項と定数項が任意であり, 従って二つの項とも 0 とおけ る。(この部分は任意である。）

\section{5. 非線形多変数系の MRACS}

この節では非線形多変数系に対する MRACS の構成法に ついて述べる。ここでは，まず，概略を述べてから例題を 用いて実際に MRACS を構成する手法を述べる。

〈5・1 MRACS 構成の概略 制御対象は未知パラ メー夕を持っているので $N(p), a(x), \Lambda(x)$ はそれぞれ $N(\psi, p), a(\theta, x), \Lambda(\phi, x)$ と書くことができる。ここで, $\psi, \theta, \phi$ は未知パラメータベクトルとする。今, 真值が分 かっているとすれば，これらは（4)式，すなわち 


$$
N(\psi, p) y=a(\theta, x)+\Lambda(\phi, x) u
$$

を満たしているので $(9)$ 式よりフィードバックおよびフィー ドフォワードを

$$
\begin{aligned}
& u=\Lambda^{-1}(\phi, x)\{-a(\theta, x)+v\} \\
& v=N(\psi, p) G_{d}(p) r
\end{aligned}
$$

とおくことにより，規範入力（コマンド） $r$ から出力 $y$ ま での閉ループ伝達行列は $G_{d}(p)$ となりモデルマッチングが 構成される。ここで, $G_{d}(p)$ は $N(\psi, p) G_{d}(p)$ がプロパー となるように選ばなくてはならない。

一方，これらのパラメータが未知である場合は，それら の推定值 $\hat{\psi}(t), \hat{\theta}(t), \hat{\phi}(t)$ を用いて適応フィードバック, 適 応フィードフォワードを

$$
\begin{aligned}
& u=\Lambda^{-1}(\hat{\psi}(t), x)\{-a(\hat{\theta}(t), x)+v\} \\
& v=N(\hat{\phi}(t), p) G_{d}(p) r
\end{aligned}
$$

により構成する。また, 各パラメータ推定については以下 のように行う。まず,

$$
N(\psi, p)=N_{\text {Diag }}(p)+N_{T}(\psi, p) \cdot
$$

と分解する。 $N_{\text {Diag }}(p)$ は $N(\psi, p)$ の対角行列部分であり, 対角要素は推定された次数の任意安定多項式である。また, $N_{T}(\psi, p)$ は $N(\psi, p)$ の非対角要素よりなる行列であり, 未 知パラメータはすべてこの行列に含まれる。これより，(16) 式は次のように書ける。

$$
\begin{aligned}
N_{\text {Diag }}(p) y & =-N_{T}(\psi, p) y+a(\theta, x)+\Lambda(\phi, x) u \\
& =\left[\begin{array}{c}
\Phi_{1}^{T} Z_{1}(t) \\
\vdots \\
\Phi_{m}^{T} Z_{m}(t)
\end{array}\right] \ldots \ldots \ldots \ldots \ldots
\end{aligned}
$$

この式の二つ目の等号は制御対象の未知パラメータが線形 に含まれているという仮定から成立する。ここで， $Z_{i}(t)$ は 適当なリグレッサベクトルであり， $\Phi_{i}$ は対応する未知定数 パラメータベクトルである。 $\Phi_{i}$ は $\psi, \theta, \phi よ り$ 構成され ている。ここで,

$$
N_{\text {Diag }}(p)=\operatorname{diag}\left[n_{1}(p), n_{2}(p), \cdots, n_{m}(p)\right]
$$

とおくと，(16) 式は次のように表される。

$$
y_{i}=\Phi_{i}^{T} \frac{1}{n_{i}(p)} Z_{i}(t), \quad i=1, \cdots, m
$$

未知パラメータベクトル $\Phi_{i}$ に対する推定パラメータベクト ルを $\hat{\Phi}_{i}(t)$ として, 次の推定器を導入する。 $\left(\hat{\Phi}_{i}(t)\right.$ は $\hat{\psi}(t)$, $\hat{\theta}(t), \hat{\phi}(t)$ より構成される。)

$$
\xi_{i}=\hat{\Phi}_{i}^{T}(t) \frac{1}{n_{i}(p)} Z_{i}(t), \quad i=1, \cdots, m \cdots \cdots
$$

推定誤差

$$
e_{i}=\xi_{i}-y_{i}
$$

を定義すると，同定理論より，

$$
\begin{aligned}
& \frac{d}{d t} \hat{\Phi}_{i}(t)=-G_{i} e_{i} \frac{1}{n_{i}(p)} Z_{i}(t), \\
& G_{i}^{T}=G_{i}>0, \quad i=1, \cdots, m \cdots
\end{aligned}
$$

はこの場合のパラメータ調整則のひとつである。

$\langle\mathbf{5} \cdot \mathbf{2}\rangle$ 例 題 次式で表される 2 入力 2 出力で 4 次の非線形系を考える。

$$
\left\{\begin{array}{l}
\dot{x}=f(x)+g(x) u \\
y=h(x)
\end{array}\right.
$$

ただし $, x \in R^{4}, u, y \in R^{2}$ であり, $f(x), g(x), h(x)$ は それぞれ次式で表されるものとする。

$$
\begin{aligned}
f(x)= & {\left[\begin{array}{c}
a_{1} x_{1}^{2}+a_{2} x_{2} \\
a_{3} x_{1} x_{3} \\
-a_{4} x_{1}+a_{5} x_{3} \\
0
\end{array}\right] } \\
g(x)= & {\left[\begin{array}{cc}
0 & 0 \\
0 & a_{6} \\
a_{7} & 0 \\
a_{8} & 0
\end{array}\right], h(x)=\left[\begin{array}{l}
x_{3} \\
x_{4}
\end{array}\right] }
\end{aligned}
$$

ここで, 各変数は $x=\left[x_{1}, x_{2}, x_{3}, x_{4}\right]^{T}, y=\left[y_{1}, y_{2}\right]^{T}$, $u=\left[u_{1}, u_{2}\right]^{T}$ とする。また, パラメータ $a_{1} \sim a_{8}$ は未知 定数であり， $a_{i}$ の真值はすべて 1 ，すなわち

$$
a_{i}=1 \quad(i=1,2, \cdots, 8)
$$

とする。このように，ここで対象とするシステムは未知パ ラメータを線形で含んでいるようなシステムである。

$h(x)$ のリー微分を用いて $T_{1}(x), T_{2}(x), T_{3}(x), \cdots$ を 求めると以下のようになる。

$$
\begin{aligned}
& T_{1}(x)=L_{g} h(x)=\left[\begin{array}{ll}
a_{7} & 0 \\
a_{8} & 0
\end{array}\right]=\left[\begin{array}{ll}
* & 0 \\
* & 0
\end{array}\right] \\
& T_{2}(x)=L_{g} L_{f} h(x)=\left[\begin{array}{cc}
a_{5} a_{7} & 0 \\
0 & 0
\end{array}\right]=\left[\begin{array}{cc}
* & 0 \\
0 & 0
\end{array}\right] \\
& T_{3}(x)=L_{g} L_{f}^{2} h(x)=\left[\begin{array}{cc}
a_{5}^{2} a_{7} & -a_{2} a_{4} a_{6} \\
0 & 0
\end{array}\right]=\left[\begin{array}{cc}
* & * \\
0 & 0
\end{array}\right]
\end{aligned}
$$

ここで記号 “*”は非零未知定数とする。これらを用いてイン タラクタアルゴリズムを忠実に実行すると次のようになる。

[Step 1] $\Gamma_{1}$ を考える。

$$
\Gamma_{1}=T_{1}^{T}=\left[\begin{array}{cc}
* & * \\
0 & 0 \\
\uparrow &
\end{array}\right]
$$


であるので，“个”の列 $\gamma_{1}^{1}(x)$ が “generic”な意味で独立列と して選ばれる。これより $q_{1}=1$ となる。

[Step 2] $\Gamma_{2}$ を考える。

$$
\begin{gathered}
\Gamma_{2}=\left[\begin{array}{cc}
T_{1}^{T} & 0 \\
T_{2}^{T} & T_{1}^{T}
\end{array}\right]=\left[\begin{array}{cc|cc}
* & * & 0 & 0 \\
0 & 0 & 0 & 0 \\
\hline * & 0 & * & * \\
0 & 0 & 0 & 0
\end{array}\right] \ldots \\
\uparrow \\
\uparrow
\end{gathered}
$$

であるので, [Step 1] の結果と行列 $\Gamma_{2}$ の構造より $\gamma_{1}^{2}(x)$ が 自動的に独立列として選ばれる。 $\Gamma_{2}$ にはこれ以外には独立 列となる列ベクトルは存在しない。（複数の列べクトルは各 ベクトルから行に重複なく非零要素が選べるとき "generic” な意味で互いに独立であるという。）このステップにおいて $q_{2}=1$ が得られる。

[Step 3] $\Gamma_{3}$ を考える。

$$
\Gamma_{3}=\left[\begin{array}{ccc}
T_{1}^{T} & 0 & 0 \\
T_{2}^{T} & T_{1}^{T} & 0 \\
T_{3}^{T} & T_{2}^{T} & T_{1}^{T}
\end{array}\right]=\left[\begin{array}{cc|cc|cc}
* & * & 0 & 0 & 0 & 0 \\
0 & 0 & 0 & 0 & 0 & 0 \\
\hline * & 0 & * & * & 0 & 0 \\
0 & 0 & 0 & 0 & 0 & 0 \\
\hline * & 0 & * & 0 & * & * \\
* & 0 & 0 & 0 & 0 & 0
\end{array}\right]
$$

であるので, $\Gamma_{3}$ の構造より $\gamma_{1}^{3}(x)$ が自動的に独立列として 選ばれる。さらに, $\gamma_{2}^{3}(x)$ も "generic”な意味で独立な列と して選ばれる。すなわち，

$$
q_{3}=2(=m)
$$

となり, [Step 3] ではじめて

$$
\operatorname{rank} \Gamma_{3}=\operatorname{rank} \Gamma_{2}+2=\operatorname{rank} \Gamma_{2}+m \cdots \cdots
$$

となるので, $w=3$ が得られる。また, [Step 3] までで得 られた独立列の組み合わせより

$$
k_{1}=1, \quad k_{2}=3(=w)
$$

が得られる。従って, 性質 1 よりシステム $(26)(27)$ に対す るインタラクタは 3 次の行プロパな左下三角多項式行列

$$
N(\psi, p)=\left[\begin{array}{cc}
n_{1}(p) & 0 \\
n_{21}(\psi, p) & n_{2}(p)
\end{array}\right]
$$

となる。ここで, $n_{1}(p), n_{2}(p)$ はそれぞれ $k_{1}=1$ 次, $k_{2}=3$ 次の任意安定多項式であり, $n_{21}(\psi, p)$ は定数項 と 1 次の項が 0 である未知係数を持った高々 3 次の多項式 である。これらの多項式をここでは以下のように設定する。

$$
\begin{aligned}
n_{1}(p) & =p+1 \\
n_{2}(p) & =p^{3}+6 p^{2}+11 p+6 \\
n_{21}(\psi, p) & =\psi_{1} p^{3}+\psi_{2} p^{2}
\end{aligned}
$$

ここで, $\psi_{1}, \psi_{2}$ はインタラクタ方程式を満たす未知定数 パラメータであり, 未知パラメータ $a_{i}$ の関数である。イン タラク夕を用いると, 非線形系 (26), (27) の入出力は (4) 式を満たすので，次式を得る。

$$
\begin{array}{r}
{\left[\begin{array}{cc}
n_{1}(p) & 0 \\
n_{21}(\psi, p) & n_{2}(p)
\end{array}\right]\left[\begin{array}{l}
y_{1} \\
y_{2}
\end{array}\right]} \\
=a(\theta, x)+\Lambda(\phi, x)\left[\begin{array}{l}
u_{1} \\
u_{2}
\end{array}\right] \ldots \ldots
\end{array}
$$

この例題では,

$$
\begin{aligned}
L_{f} h(x)= & {\left[\begin{array}{c}
-a_{4} x_{1}+a_{5} x_{3} \\
0
\end{array}\right] } \\
L_{f}^{2} h(x)= & {\left[\begin{array}{c}
-a_{4} a_{5} x_{1}-a_{4} a_{2} x_{2}+a_{5}^{2} x_{3}-a_{1} a_{4} x_{1}^{2} \\
0
\end{array}\right] } \\
L_{f}^{3} h(x)= & {\left[\left(\begin{array}{c}
-a_{4} a_{5}^{2} x_{1}-a_{2} a_{4} a_{5} x_{2}+a_{5}^{3} x_{3} \\
-a_{1} a_{4} a_{5} x_{1}^{2}-2 a_{1}^{2} a_{4} x_{1}^{3} \\
-2 a_{1} a_{2} a_{4} x_{1} x_{2}-a_{2} a_{3} a_{4} x_{1} x_{3} \\
0
\end{array}\right]\right.}
\end{aligned}
$$

であるので, (11) 式より

$$
\begin{aligned}
a(x) & =\left[\begin{array}{c}
\theta_{1}^{T} \zeta_{1}(t) \\
\theta_{2}^{T} \zeta_{2}(t)
\end{array}\right] \\
\zeta_{1}(t) & =\left[x_{1}, x_{3}\right]^{T} \\
\zeta_{2}(t) & =\left[x_{1}, x_{2}, x_{3}, x_{1}^{2}, x_{1}^{3}, x_{1} x_{2}, x_{1} x_{3}\right]^{T} .
\end{aligned}
$$

と書ける。ここで $\theta_{i}(i=1,2)$ は対応する未知パラメータ ベクトルである。さらに, $(11)(29)(37)$ 式より

$$
\Lambda(x)=\left[\begin{array}{cc}
a_{7} & 0 \\
11 a_{8}+\psi_{2} a_{5} a_{7}+\psi_{2} a_{5}^{2} a_{7} & \phi_{1} a_{2} a_{4} a_{6}
\end{array}\right]
$$

となることから, 新たに未知定数 $\phi_{1}, \phi_{2}, \phi_{3}$ を導入して

$$
\Lambda(\phi, x)=\left[\begin{array}{cc}
\phi_{1} & 0 \\
\phi_{2} & \phi_{3}
\end{array}\right]
$$

とおく。

以上より $(36)$ 式は次のように書ける。

$$
\left\{\begin{array}{l}
y_{1}=\Phi_{1}^{T} \frac{1}{n_{1}(p)} Z_{1}(t) \\
y_{2}=\Phi_{2}^{T} \frac{1}{n_{2}(p)} Z_{2}(t)
\end{array}\right.
$$

ここで 


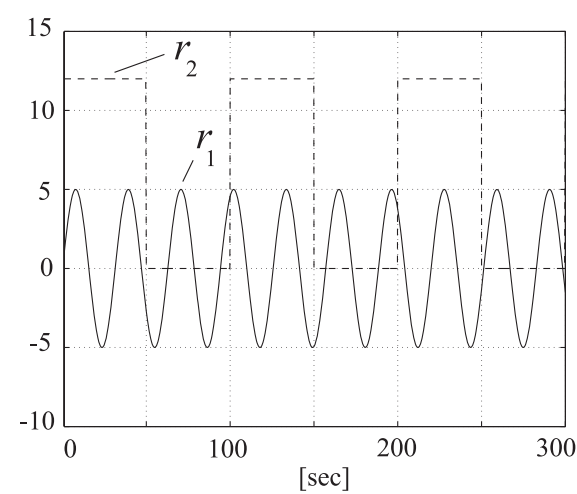

Fig. 1. Reference Input Signals $\left(r_{1}\right.$ and $\left.r_{2}\right)$

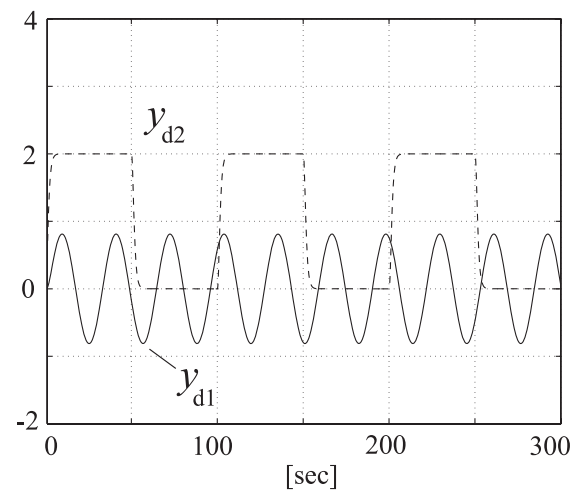

Fig. 2. Output Signals of the Reference Model ( $y_{d 1}$ and $\left.y_{d 2}\right)$

$$
\begin{aligned}
& Z_{1}(t)=\left[x_{1}, x_{3}, u_{1}\right] \\
& Z_{2}(t)=\left[\frac{p^{3}}{n_{2}(p)} y_{1}, \frac{p^{2}}{n_{2}(p)} y_{1}, x_{1}, x_{2}, x_{3}, x_{1}^{2},\right. \\
&\left.x_{1}^{3}, x_{1} x_{2}, x_{1} x_{3}, u_{1}, u_{2}\right]
\end{aligned}
$$

であり, $\Phi_{1}=\left[\theta_{1}^{T}, \phi_{1}\right]^{T}, \Phi_{2}=\left[-\psi_{1},-\psi_{2}, \theta_{2}^{T}, \phi_{2}, \phi_{3}\right]^{T}$ は対応する未知パラメータベクトルである。この例題では これらの真值は次の通りである。

$$
\begin{aligned}
& \Phi_{1}=[-1,2,1] \\
& \Phi_{2}=[1,5,6,6,-6,6,2,2,1,5,1]
\end{aligned}
$$

(42) 式に対してパラメータ同定器を

$$
\left\{\begin{array}{l}
\xi_{1}=\hat{\Phi}_{1}^{T}(t) \frac{1}{n_{1}(p)} Z_{1}(t) \\
\xi_{2}=\hat{\Phi}_{2}^{T}(t) \frac{1}{n_{2}(p)} Z_{2}(t)
\end{array}\right.
$$

この例では $n_{1}(p)$ が 1 次（安定）多項式であるので上式の ようにおいた。パラメータ調整則は

$$
\begin{cases}\dot{\hat{\Phi}}_{1}(t)=-G_{1} e_{1} \frac{1}{n_{1}(p)} Z_{1}(t), & e_{1}=y_{1}-\xi_{1} \\ \dot{\hat{\Phi}}_{2}(t)=-G_{2} e_{2} \frac{1}{n_{2}(p)} Z_{2}(t), & e_{2}=y_{2}-\xi_{2}\end{cases}
$$

これらの調整則は

$$
V(t)=\sum_{i=1}^{2}\left(\hat{\Phi}_{i}-\hat{\Phi}_{i}(t)\right)^{T} G_{i}^{-1}\left(\hat{\Phi}_{i}-\hat{\Phi}_{i}(t)\right)
$$

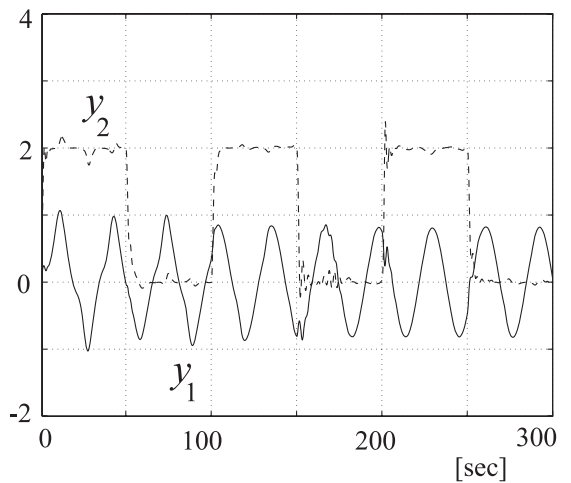

Fig. 3. Output Signals of the Plant $\left(y_{1}\right.$ and $\left.y_{2}\right)$

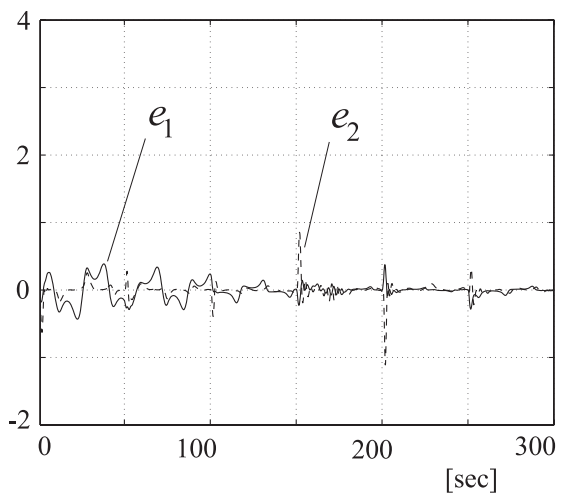

Fig. 4. Output Error Signals $\left(e_{1}\right.$ and $\left.e_{2}\right)$

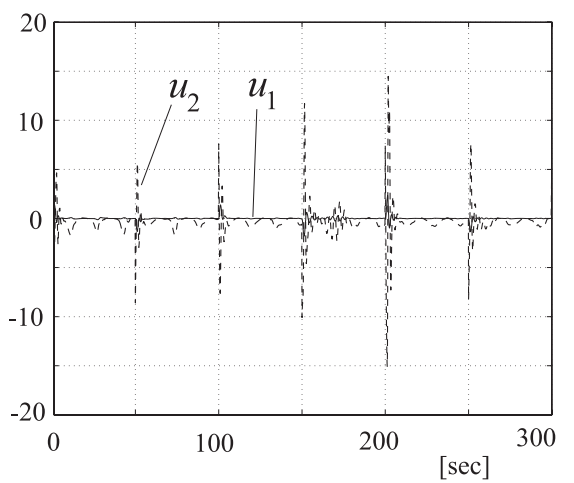

Fig. 5. Adaptive Input Signals $\left(u_{1}\right.$ and $\left.u_{2}\right)$

をリアプノフ関数として用いている。ここでは, 以下の数 值例を用いたシミュレーション結果を示す。

$$
\begin{aligned}
& \hat{\Phi}_{1}(0)=[-4,6,3] \\
& \hat{\Phi}_{2}(0)=[2,3,2,2,-2,2,1,2,1,10,2] \\
& G_{1}=\lambda I, \quad G_{2}=\lambda I, \quad \lambda=10
\end{aligned}
$$

規範モデルは次式とした。

$$
\left[\begin{array}{l}
y_{d 1} \\
y_{d 2}
\end{array}\right]=\frac{1}{n_{2}(p)}\left[\begin{array}{ll}
1 & 0 \\
0 & 1
\end{array}\right]\left[\begin{array}{l}
r_{1} \\
r_{2}
\end{array}\right] \ldots \ldots \ldots
$$

規範入力, 規範出力, プラント出力, 出力誤差, 適応入 力をそれぞれ図 1 図 5 に示す。ここで示した例題は，平 均的なシミュレーション結果である。規範入力の一つに矩 
形波を用いているため，不連続に変化する箇所で制御系が 変動しているが，規範入力に連続関数を利用した場合は応 答はかなり良好になる。

なお, (36)(37) 式よりこのプラントの相対次数は 4 とな り, 次数も 4 であることから，ゼロダイナミクスを持たず， いわゆる「最小位相性」の仮定は満足している。

\section{6. あとがき}

本論文では線形多変数系に対する MRACS 設計のフレー ムワークが静的状態フィードバックにより入出力線形化可 能なアファイン型の非線形多変数系にたいして適用可能で あることを示した。すなわち，このクラスの非線形系では 定数係数行列を持つインタラクタが得られることから，こ れを利用して未知プラントの事前情報を使いながら適応系 のためのプラントの別表現を得る手法について述べた。一 旦，この別表現が得られれば，ここで利用した適応系ばか りではなく線形系で培ったいくつかの適応系が利用できる こととなる。

なお，ここでは適応系全系の信号の有界性についての証明 については述べていない。(12)(13) 式で表わされるシステム はパラメータ調整を除いたプラントを表しているが（フィー ドバック後), ここではプラントの入出力関係を規範モデル に合わせることを目指しているので，(12) 式のみが考察の 対象になっている。すなわちゼロダイナミクスに関係する (13) 式は無視して適応系を構成しているので, この理論的 考察がまだ不完全なためである。一般的にこの種の非線形 安定化問題は，(13) 式を状態変数 $z$ を用いて安定化するた めのリアプノフ関数とその微分した関数が既知であるとい う仮定をした上でバックステッピングを利用することが多 いが，適応系の場合はその仮定は極めて大きいので，この 点については今後の課題としたい。

(平成 20 年 6 月 6 日受付, 平成 20 年 12 月 28 日再受付)

\section{文献}

(1) W.A. Wolovich and P.L. Falb: "Invariants and Canonical Forms under Dynamic Compensation", SIAM J. Control and Optimization, Vol.14, pp.996-1008 (1976)

(2) L. Dugard, G.C. Goodwin, and C.E.de Souza: "Prior Knowledge in Model Reference Adaptive Control of Multiinput Multioutput Systems", IEEE, Trans. on Automatic Control, Vol.AC-29, pp.761-764 (1984)

(3) H. Elliott and W.A. Wolovich: "Parametrization Issues in Multivariable Adaptive Control", Automatica, Vol.25, pp.533-545 (1984)

(4) Y. Mutoh and R. Ortega: "Interactor Structure Estimation for Adaptive Control of Discrete-Time Multivariable Nondecouplable Systems", Automatica, Vol.29, pp.635-647 (1993)

(5) P.W. Gibbens, C.A. Schwartz, and Minyue Fu: "Achieving Diagonal Interactor Matrix for Multivariable Linear Systems with Uncertain Parameters", Automatica, Vol.AC-29, No.6, pp.1547-1550 (1993)

(6) R.P. Singh and K.S. Narendra: "Prior Information in the Design of Multivariable Adaptive Controllers", IEEE Trans. on Automatic Control, Vol.AC-29, pp.1108-1111 (1985)

(7) A. Isidori: "Nonlinear Control Systems", Springer-Verlag, New York (1989)

(8) R. Marino and P. Tomei: "Nonlinear Control Design", Prentice-Hall (1995)
武 藤 康 彦 (正員) 1977 年 3 月上智大学大学院修士課程修

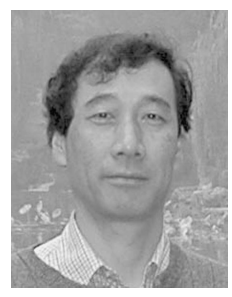
了。同年三菱スペースソフトウェア（株）入社。 1981 年上智大学大学院博士課程修了。同年上智大 学理工学部助手。同講師, 助教授を経て現在教授。 Saskatchewan 大学（1983 年, カナダ), CNRSUTC（1995 年, フランス), CNRS-SUPELEC (2006 年, フランス) の客員研究員。適応制御, 時変系の制御, 多変数制御系, 非線形制御制御系 などの研究に従事。工学博士。計測自動制御学会, IEEEの会員。 